\title{
A Democracy of Children's Literature Critics? The Opportunities and Risks of Paying Attention to Open Reviews and Mass Discussion
}

\author{
Dena $\operatorname{Attar}^{1}$ (D)
}

Published online: 12 May 2017

(C) The Author(s) 2017. This article is an open access publication

\begin{abstract}
Drawing on the outputs of a wider democracy of online reviewers presents the academic study of children's literature with opportunities and challenges, and can enhance critical discussion. As it is now easy to locate a large number of online reviews, it is argued that children's literature studies needs to make room for a wider range of critical voices. This article reports on the work of two cohorts of over a thousand students. Each cohort, in consecutive years, researched online reviews as part of their studies in contemporary children's literature on a one year part-time module at a distance learning university. Despite the perceived lack of status of non-academic, non-professional critiques, students' and tutors' experiences of these tasks showed the value of researching online reviews. This work also allowed for alternative forms of writing and assessment alongside more conventional academic essays, and encouraged students to develop their skills of critical digital literacy. Module leaders recommended basic initial research methods for student use, but for more extensive or larger scale research it will be important to address methodological issues and understand how online reviewer communities operate. Such changes in approaches to teaching and learning also need to take into account the issues surrounding social media usage, ownership and control.
\end{abstract}

Keywords Online reviews · Social media - Digital literacies · Picturebooks · YA fiction · Children's literature criticism

\footnotetext{
Dena Attar was a Senior Lecturer in the School of Languages and Applied Linguistics at The Open University, where she chaired a Children's Literature third level module for 7 years, and is now an Honorary Associate. She has researched boys' and girls' reading in UK primary schools, adults' gendered online literacy practices and nineteenth century domestic literature.
}

\section{Dena Attar}

Dena.Attar@open.ac.uk; dena.attar@btinternet.com

1 School of Languages and Applied Linguistics, The Open University, London, UK 


\section{Introduction}

The first part of this article argues for a role within children's literature studies for a wider range of critical voices. In the second part I report on the work of a large cohort of students at one university who researched online reviews as part of their studies in contemporary children's literature. Students' experiences provided evidence supporting the value of such an inclusion, and correspondingly tutors and module leaders identified advantages and implications for teaching in higher education. The methodological issues in relation to online resources certainly need attention, and the third part of this article considers how some large online reviewer communities operate and how they might be researched. The final section examines what the wider democracy of online reviewers can add to the critical discussion of sample texts, and the wider opportunities and challenges this presents for the academic study of children's literature.

Interested and informed people of all ages can and do now publish critiques of works of children's literature to potentially large audiences online. On the grounds of volume alone there is a case for considering how to acknowledge and attend to this more recent range of accessible criticism that is neither professional nor academic. Innumerable platforms now offer relatively equal access with few barriers to expressing opinions online. Those using them to comment on children's books to an unknown audience might be termed, collectively and perhaps provocatively, a democracy of children's literature critics. These critics have not been completely ignored by the academic community, but neither have they been paid much serious attention. Their openly published responses to children's literature could figure among topics of interest to scholars in the field, and have the potential to contribute insights that might otherwise be missed. At a time when universities often need to foster critical digital literacies and are under pressure to adapt traditional assessment methods, requiring students to research, compile and analyse non-academic online reviews gives scope for achieving both of those aims.

Resistance to using such informal resources may come from more than one direction. Traditionally and by convention, students of children's literature in formal learning contexts have been expected to turn from their primary texts to academic criticism, perhaps with an occasional leavening of professional reviews, and to accept a hierarchy in terms of what counts as relevant secondary literature. Unless alternative sources are a specified research area in themselves, at undergraduate level they have counted for much less than academic criticism or professional reviews in high status publications such as mainstream newspapers. In Barbara Hoffert's words, "The traditional review has always been defined by the idea of authority" (2010, p. 22). Academic studies are likewise supported by the idea of authority but paradoxically, in asking students to read alternatives, teachers can make explicit the values of objectivity, well-founded argument and depth of analysis that ought to distinguish the recommended academic literature, and can then foreground the reasons why other writing may differ in ways that mean it can be an adjunct but not a substitute. Less pejoratively, and arguably in a more democratic spirit, we could describe all secondary sources as representing a range of 
context-dependent literacy practices rather than a hierarchy reaching down from the writing of academic experts to the inadmissible opinions of ordinary readers. Nonprofessional, non-academic critics can often represent views of value to researchers for their grounding in direct experience as teachers, parents or readers, whether selfdepicted as the primary audience or as responsible purchasers.

Reader response as considered within the study of children's literature, as discussed by Rosemary Ross Johnston (2011), Maria Nikolajeva (2014), Dena Attar and Janet Maybin (2016) and for instance in the work of Evelyn Arizpe and Morag Styles (2015) tends to refer either to a controlled educational context, or a therapeutic context. As an adjunct to the study of children's literature more generally it raises problems both methodologically and for theory. Students are often warned not to confuse the abstract child in the text, or the equally abstract child positioned by the text, with an actual child or child reader. Occasionally academic critics themselves nevertheless do make the turn from a particular text and its contexts of production to positing how (other) readers might be influenced by it, thus eliding distinctions between the theoretical positioning of notional readers and real life influences on actual readers. This move, and any claims it involves, may or may not be openly acknowledged and some academic critics see it as a trap to be avoided (Rudd for instance (2013) analyses several perhaps unwitting examples). Marah Gubar (2013) on the other hand argues that the "risky business" of talking about children in children's literature criticism cannot be avoided, while Perry Nodelman (2016) defends it unapologetically, on the basis that expert critics play a valuable role in uncovering the ways in which young readers may be unknowingly influenced by a text. While scholars continue debating whether discussing a real child reader's response abandons theory and analytic skill for speculation, there is agreement that real readers' responses can differ, even when it is argued (Nodelman, 2016) that some general influence must still exist and can be deduced and analysed. References to actual influences on readers persist in children's literature studies as a minor, occasionally troubling theme, not always recognising young readers' diversity. These complexities, awkward and contested as they are, should not stop us seeking ways to include evidence of readers' responses. There are opportunities as well as problems for any academic critic wishing to cross the line from discussing how the abstract young reader is positioned, to making claims about a less abstract one who has read and commented on the text. The goal should be to contextualise and evaluate such evidence, mediated as it must always be like any response evidence, rather than to use it selectively in support of any desired conclusions or analysis.

Other possible resistance to utilising online reviews could derive from concerns about the quality and authenticity of data retrieved from commercial platforms. Such reservations are well justified but the diversity, scope and potential volume of data mean it can still be studied without misrepresentation as evidence of the discussion of children's literature at large and in public, provided the platforms' constraints are understood and taken into account. In dealing with such concerns teaching must therefore be grounded in critical understanding of new media infrastructures. 


\section{From Hierarchies to a Range of Literacy Practices}

Theories of literacy as comprising a range of practices, as in the influential work of Brian Street (1995) and David Barton et al. (2000) are useful to draw on to account for the types of reading and writing accomplished in diverse contexts, and to see the particular features of online reviews as appropriate to their context rather than as deficient. In relative terms, academic criticism as a form of academic literacy has its own distinctive features, being an activity with purposes beyond the discussion of any one work or unearthing, critiquing and theorising ideological representations in individual texts to furthering critical understandings of power structures and the social world. Conventionally, it does some things and not others. One highly conventional feature is the occasionally vexing assumption that its readers will be familiar with any text under discussion, along with any others mentioned in passing. Descriptions and summaries are therefore unnecessary and it is immaterial whether or not there are revelations about how a story ends, so there are no spoiler alerts. While academic criticism can be influenced by trends not only with regard to theory but to texts' popularity and mass consumption, it is somewhat immune to sales figures. The latest publishing phenomenon might receive a lot of attention but might equally be ignored. Older and obscurer titles can still claim academic interest at any time.

Professional reviewers specialising in children's literature (for example and in particular, those paid to write reviews for print media) abide by contrasting conventions. They are expected to introduce and comment on the latest publications: that is their key role. Much to authors' frustration, they review few new titles since they can only sample a small fraction of the huge number published every year. Reviewers focus on a small number of titles, perhaps one a week, mostly chosen as recommendations, and will generally explain who they think would be likely to enjoy each book. Mainstream press critics often concentrate on writing positive reviews (Eccleshare, 2015) to avoid wasting scarce space on books they cannot promote to readers and purchasers. Professional reviewers usually take great care not to give away the ending of a story.

These obvious simplifications focus on a few features rather than on the recognised value of academic and professional criticism and reviews, but the point is to contrast them with the output of a wider democracy of online reviewers who do not share these specific aims, constraints or accountabilities, but do have others. Their commentaries on children's literature outside such parameters can span a much greater range, not least in what they choose to comment about. At a surface level, for example, these other critics will often provide a detailed description but usually obey the professionals' convention not to give away the ending, or if they are going to do so, might write 'SPOILER ALERT'! They may narrate their own or a family member's experience of reading the book, dwelling on personal response, in a similar way to the narration of experiences in consumer reviews on travel websites Camilla Vásquez $(2013,2014)$ found to be typical. They may discuss who would or would not enjoy it, drawing on personal experience, knowledge or guesswork. They may engage in arguments with other reviewers, challenging 
someone else's interpretation, or others' statements about suitable or unsuitable content for an age group. They may refer to wider debates including published reviews and articles, or discuss the author's other works and life story. They may selfidentify as having a specific connection to a theme or character in a story, commenting critically from a position of expert knowledge and understanding. Rarely, they may adopt a more academic approach (and might get the response that on this particular site no one wants to read an essay).

Other and arguably more important distinctions between online reviews and solitary academic critiques or professional reviews rely on the potential affordance of mass access to enable a form of direct debate and discussion. In these relatively open online spaces there can be a massing of both similar and divergent opinions, appearing more immediate than the debates students are expected to extrapolate from academic publications. Online professional reviews might allow comments, but the status distinction between above-the-line professional and below-the-line amateur viewpoints remains clear, is embedded in website structure and can be enforced through moderation practice. In contrast, while massed reviews on a site without such inbuilt distinctions may never transform into a collective opinion or a community of debaters, they do have that potential and sometimes fulfil it, as a single visible space can collect and present many individual experiences and contrasting perspectives. Extensive online reviews of The Hunger Games trilogy (Collins, 2008, 2009, 2010) offer a good example of a debating community since a topic that comes up frequently, although in the academic literature it is of little interest, is how similar it is to the Japanese novel, film and manga Battle Royale. Numerous reviewers demonstrate engagement with other comments, sometimes with lengthy accounts of why they consider The Hunger Games better, worse or substantially different, for example "While many point out the similarities with Battle Royale and there are many the striking difference is in how the contestants are assembled and also that they receive training of a sort" (Kindle Customer, 2013). Others comment on whether originality matters, for instance Amazon Customer (2012) "I've heard the rumblings about how much this story is nearly identical to Battle Royale [sic], but honestly, I don't really care...neither story is totally original".

A final distinction underpinning the concept of a democracy of critics is that unlike much academic or professional writing, the mass of opinion hosted on freely available websites is accessible at little or no cost, and that in turn means potentially many millions more readers. Despite efforts to make research publications more accessible, academic criticism is still a rarefied domain. Online reviews have greater reach and therefore potentially more influence than publications by academic experts. This cuts both ways, as it is also a reminder of an important task for academics who cannot assume their expert knowledge and opinion will automatically be valued, but are under pressure to establish their case with both students and the wider public.

Within literacy practices research generally (see for example Ilana Snyder, 2002; Kathy Mills, 2014; Philip Seargeant and Caroline Tagg, 2014), dominant themes have been the shaping effects of contexts and online communities, influencing how people acquire, develop and pass on their practices. In the wider fields of internet 
studies dating back to the 1990s there has been tension between a focus on the apparently open, democratising, social, community-building and empowering features of online spaces and the identification of continuing barriers to access, hidden controls, and the marketisation of consumers' (potentially anyone's and everyone's) interests and online activities. Nancy Baym (2015) for example in an overview article notes that the very term "social media" "obscures the unpleasant truth that "social media" is the takeover of the social by the corporate". The concept of a democracy of critics sits somewhere in between these positions, linked as it is to consumption and marketing but also to both notional online and real offline communities. Nick Couldry and José van Dijck (2015, p. 2) point out that since "the social is big business", research needs to take a critical rather than celebratory or merely descriptive stance towards social media practices. "It must mean at least researching how social media platforms (and the plural production cultures that generated them) have come to propose a certain version of "the social," and how users go on to enact it". The social democracy of critics which arguably comes into existence in some online spaces results from the enactments of "social" or of "community" built on top of, and encouraged by, commercially-oriented sites that seek to profit from them. It effectively becomes part of their advertising, but as it was not usually written for that purpose, that does not invalidate all aspects of such democratic criticism. It can still provide examples of social or community endeavour and criticism, informing an understanding of the wider reception of children's literature, even allowing for the "big business" frame around it. The enactors are not inevitably bound tightly within the frame. Expecting students to refrain from using highly accessible online resources is no longer realistic, but asking them to draw on such resources for specific purposes gives teachers the opportunity to stress criticality. As Gregory Downey argues (2014, p. 143), university teachers need to discuss students' inevitable use of "these extraordinary technologies, Google or Wikipedia or Facebook or Amazon" to help break through a "narrow, instrumental, and rather triumphalist understanding of new media infrastructures".

Once criticism of children's literature is seen in terms of a spectrum of literacy practices, academic, professional and popular, rather than as an unquestionable hierarchy, it is easier to take a more positive view of unorthodox texts as both objects and means of research, in an academic context. They can become opportunities to identify ranges of voices and purposes as well as responses. As outlined in the next section, this was the approach taken on a children's literature module when undergraduate students were asked to research and select reviews, in order to compile a collective broad account of contemporary trends.

\section{Taking a Broader Range of Reviews into Account: The Experience of One Children's Literature Course}

In 2015 almost 1200 students who were distance learners at a UK university studying a third level undergraduate module were required to locate and discuss reviews of recent works of children's literature, firstly for an online collaborative activity, and later for part of a coursework assignment. The task was re-run the 
following year, again with over a thousand students and with a few minor modifications to address procedural issues reported from the first year. Students worked both independently carrying out online research to find publicly available reviews, and in groups where they shared and discussed their findings. The groups then co-wrote wiki pages commenting on a chosen text and on their compilation of selected reviews. These jointly created pages were in turn shared more widely as they were made accessible to all the students and tutors on the module.

At the end of each year almost three hundred student-created wiki pages were produced and made available for the entire cohort to read, covering a large number of works of children's literature along with an overview of some of the conversations about them being conducted in various public online spaces. For their final coursework assignment, students were asked to draw on these newly created resources in discussing contemporary trends in children's literature. The activity gave students an opportunity to discover a broader range of children's literature and young adult fiction, particularly works published too recently to be featured much in academic criticism. It enabled students to take an informed part in online discussions, an important aspect of their experience in a distance learning university. The most novel, and for some of those teaching the module the most controversial aspect, was the third aim of allowing students to research and draw on resources which were neither the primary literature nor its associated academic criticism, but other forms of writing unlike traditional academic articles or books. This third purpose required students to pay serious attention to the much larger conversation about children's literature taking place outside the academy.

In the first year, the module team collected data on students' participation and outputs and on tutors' experiences and attitudes, using a range of quantitative and qualitative methods including anonymised online surveys, interviews and reflective reports, and analyses of sample contributions. Students' collective research outputs and their feedback to end-of-course surveys showed their realisation that they had extended their knowledge and understanding beyond the confines of the module's set reading. They made comments such as "I was made aware of new trends in young adult fiction"; "The wiki helped me discover books I would now like to read"; "The online wiki activity was unexpectedly useful for bringing together all that we had learnt so far up to that point"; "It offered an insight into more recent children's literature and added a current feel to the module"; "a good chance to interact with fellow students and also a fantastic opportunity to broaden our reading of children's literature". Some feedback even identified what the module's required reading had lacked in relation to the wider range they had explored themselves. In future such more challenging insights could further critical discussion about what gets studied and why. Discussion might interrogate not only the mechanisms promoting specific titles commercially but the existence of a canon in children's literature studies, whether referring back to the Children's Literature Association's sponsorship of the 1980s Touchstones series, or to current titles given privileged status in academic studies.

Students also noted learning to appreciate younger readers' perspectives from reading reviews, noticing a frequent gulf between adult and younger reviewers, and finding that adult reviews often tended to include a somewhat automatic moral 
response. One such discovery students described was that while for adult reviewers the use of obscenities in children's books appeared relatively uncontroversial, images of characters smoking were currently highly controversial, for example in reviews of Julia Donaldson's The Scarecrow's Wedding (2014). Tutors noted some good examples of students moving from informal to more formal discussion, "people within the group who could relate [reviews] to the themes of the module and were more analytical", for instance students becoming more aware of the prominence and popularity of celebrity authors such as David Walliams and Zoe Suggs, and commenting on how that fitted critiques they had studied in the module of a changing publishing industry. Students identified current sub-trends such as a concentration on disability, illness and death in young adult fiction, arguing that themes previously labelled difficult were now commonplace and did not disturb young readers. They argued, again from more recent evidence, that postmodern picturebooks were no longer innovative as their module reading claimed but had instead become a new norm. Moving from the personal response found in individual reviews to collective summaries helped students develop difficult skills of criticality, a phenomenon noted by Amy Kennedy when setting students work which had similarities in terms of research, collation and commentary (Kennedy, 2012).

As this was a relatively minor part of their coursework and they had limited time, students were not expected to undertake systematic data collection, provide in-depth analyses of online reviews or details of research methodology. Procedurally, groups were advised to make a selection of reviews along lines that would give them angles for discussion, such as being able to compare adults' and young readers' reviews, locating negative as well as positive comment, or comparing celebratory reviews by adults of award-winning books with responses from children in school-based reading groups. The guidance gave only succinct advice on methods and approaches, encouraging students to research particular claims or reservations about suitability; recommendations for usefulness or value such as statements about who or what a text was especially good for; differences of opinion; a range of voices. They were also advised to seek out any evidence of reviewers' standing, as far as it was possible to know, and who they were addressing, e.g. professional critics paid by newspapers; teachers or carers, recommending titles to other teachers or carers; young readers giving their ages and writing for their peers. The guidance also noted that young readers may either be writing informally, or in more formal ways in settings provided by adults.

The module website supplied a list of possible starting points for students' research, indicating the range of sources they could use and emphasising that all were allowable: generalist newspapers and magazines, specialist children's literature blogs run by teachers, parents or booksellers, award sites and award shadowing sites, and retail sites such as Amazon. In fact the site students most commonly used turned out to be Amazon. In each of the first 2 years, more than a quarter of student groups included at least one Amazon review reference, resulting in a sample of around seventy wiki pages per year. Students' widespread use of Amazon reviews prompted the module leaders to look more closely at filters and other tools in order to provide more detailed guidance the following year. As this 
extract illustrates, the guidance recognised that students were likely to use the site, suggested a few methods, explained ways in which the site worked and reminded students of its commercial aims.

Amazon and other commercial organisations routinely solicit reviews from customers, via emails asking if the customer wants to rate and review an item they recently purchased. In this way sellers can add content to their websites cheaply, which in turn adds value for the company and its other customers... For the purpose of this activity you could try seeking intermediate reviews which are likely to give reasons for deciding on a less than perfect rating, e.g. $3^{*}$ or $2 *$. Amazon lets you sort negative and positive reviews, which can cut down the number to scan and save your time. It lets you see if a reviewer is a verified purchaser, although other reviewers who might have made a more deliberate decision to write a review may well have interesting comments to make. You can see if there are comments in response to reviews, which might tell you if there is any debate, for example between adult reviewers saying a book is not recommended for young readers and young readers strongly disagreeing...

It was evident in the following year from URL references provided in wiki pages pointing to a filtered result that students were indeed using these tools, for instance filtering large numbers of reviews of a book to locate the ones most likely to include detailed criticism.

On the part of tutors used to teaching more traditional literature studies there were a few concerns that students' work would lack a critical edge. They queried what students stood to gain from less traditional forms of writing or from straying so far outside the usual confines of an academic course. In response, the student-facing framing of the activity was strengthened to identify and emphasise reasons for studying children's literature specifically, as opposed to literature in general. The rationale restated why studying children's literature matters and is relevant to contemporary society, and its value for understanding changing childhoods and ideas about childhoods. As part of the rationale, it followed that larger conversations about children's literature taking place outside the academy also matter. It cannot be assumed that its participants have nothing to tell us, any more than the historical study of children's literature can be dissociated from culturally embedded ideas and debates about children and childhood in previous eras and societies.

After 2 years of running the activity a majority of tutors wanted students to be given more credit for their engagement with it, so that time spent on independent research, group discussion and collaborative writing would be valued on more equal terms with academic essay writing. This move was seen as particularly likely to benefit students who were active, constructive and well informed participants, despite having less confidence or expertise in traditional academic writing. The debate within the module itself had quickly moved on from concerns about nonacademic writing to concerns about fair ways of valuing students' work beyond assessing conventional academic skills. While some problems common to students generally with online group and collaborative work persisted, and in response module leaders shared with tutors the considerable relevant literature on innovations 
in teaching along with recommended strategies, there was clear evidence that many students were gaining broader knowledge and greater understanding.

\section{Analysing Online Reviewer Communities}

Analysing reviewer communities remained beyond the scope of students' work, but is the subject of this section. Online reviews, read by millions daily, have become essential elements of many commercial websites and have therefore already been researched to an extent. Hua-Ning Chen and Chun-Yao Huang, in a study of Amazon reviewers' behaviour (2013), note the importance and influence of online reviews and evidence that they increase sales. Clay Shirky (2008), Donald Tapscott and Anthony Williams (2007) describe how Amazon, acknowledged as the industry leader, developed an open business model based on providing access to its technologies as well as maximising user participation. Amazon fosters various levels of participation in numerous ways, eliciting reviews from purchasers through automated follow-up emails, providing guidance on writing reviews (Amazon, 2016), a rating system for reviews and reviewers which can then be filtered, and information about a reviewer's 'verified purchaser' status where that exists. Anyone with an Amazon account is able to post a review as well as respond to others' reviews. Reviewers who are using their verified real name are flagged as providing yet another emblem of trustworthiness. There are special forums for Amazon's 'top reviewer' community and even a reviewer Hall of Fame.

The company's continuing investment in its open reviewing platform gains Amazon traffic and commercial benefit, as it profits from the vast number of contributors who are in the main freely donating their time and effort. It brings risks too, and fake reviews are an ongoing problem. Amazon has sued several sites and individuals who are in the business of selling fake reviews (Economist, 2015). As far back as the late 1990s one commentator discussing the emerging democratisation of book reviewing referred to the potential for making mischievous use of the site (Economist, 1999), meaning spoof reviews intended as jokes rather than malicious criticism. There are still plenty of reviewers posting spoof reviews targeting particular products, either because an item seems to deserve ridicule or to make a more serious point. Collections of hundreds or even thousands of Amazon reviews of items such as a gadget for slicing bananas, a T-shirt design showing wolves howling at the moon, and a pink Bic pen for females illustrate how a community of pretend reviewers can form around a shared critique (pink pens for females) or joke (banana slicers), interacting with each other and keeping a joke or protest in play, like a slowly forming virtual flash-mob.

The term "community" needs to be used cautiously, although Amazon itself does use it. Researchers studying online reviews and reviewer communities such as Camilla Vásquez (2013, 2014), Marios Kokkodis and Theodoros Lappas (2015), Wenqi Shen et al. (2015) have looked at online performance, reviewer identities and creating trustworthiness, and at reviewing as a competitive income-generating activity for its most prolific participants (Shen et al., 2015). There are distinctive differences to take into account when considering how far non-specialist studies 
apply. Book reviewers are a sub-set of online reviewers generally, and those who review children's books and young adult fiction are in turn a smaller sub-set. Ultraprolific "star" reviewers, who are sent free products and see reviewing as a form of freelance work paid in kind for instance, tend to avoid reviewing books, on the grounds that it is more time-consuming, and therefore less rewarding (Shen et al., 2015). Reviewing a book is more like reviewing an experience - the experience of reading - than reviewing other consumer products that can be tried and rated immediately. Reviews that narrate experiences (e.g. of restaurants, travel and accommodation) are common on sites like TripAdvisor, as Vásquez (2013) describes. Yet book reviewers are often clearly aware that their review should do more than merely narrate a personal reading experience.

Many online book reviews do tend to narrate an experience of reading, and some will even describe the experience of receiving and first seeing a book, but more extended reviews also frequently attempt to summarise the text impersonally, drawing on and re-contextualising the language of literary criticism in evaluating the quality of its writing, and making judgement calls on behalf of other prospective readers about enjoyment or suitability. Particularly in the case of children's literature, these judgements may include recommendations for specific groups of readers, and frequently refer to the reviewer's own identity as parent, carer, teacher, or member of a specific age group as a relevant factor. These elements arguably help promote some sense of community, however transient, amongst readers and potential readers who share a similar role, characteristic or age group. There may be unmistakeable interchanges between reviewers using the response facility, or implied as well as explicit references to previous reviews, as in the debates about The Hunger Games described above. Often adult reviewers appear conscious that their own response to a text is not adequate and that they ought also to comment on whether they should recommend it to a younger reader, even when that seems an impossible task, as evidenced in statements such as "I can't vouch for what age of person might find this book most appealing, but reading it as an adult I found it delightful and compelling", or "I really struggle to imagine it holding a child's attention".

The dynamic, changing nature of websites and their simultaneous ability to act as repositories for older material together match the way children's literature fits into the lives of young readers, families and schools across time, for the duration of childhoods. Generations can share queries and responses, indirectly. Those accessing the site might as easily have an interest in titles that have been around for years and have been reviewed many times, rather than merely seeking the latest ones. The relative longevity of children's literature compared with many other consumer products means the online community of reviewers can still be effective as a collection of disparate voices stretching a conversation over time, rather than an immediate gathering of responses. With this form of persistent online communication, timeliness is relevant with respect to the needs of the searcher rather than the dates of the content. Regardless of publication or review dates, a grandparent choosing a gift for a young child may respond with thanks to a parent or teacher who reviewed a picturebook and described children's appreciation of it, for 
instance, creating a virtual exchange that spans months or even years. (The dataset Kokkodos and Lappas (2015) collected included book reviews spanning 17 years.)

With recent young adult fiction, where the currency of bestselling titles is much more significant, there are likely to be large numbers of reviews posted close in time, with reviewers mainly young readers themselves, and strong opinions leading to occasional hot debates. These clusters of reviews can look more like other dynamic online communities where there is interaction, with contributors commenting on others' views, disputing claims and engaging with critical opinions.

Children's literature reviews on Amazon and other more specialist websites display a sense of community most strongly when there is an overt sharing of interests coalescing around an example of therapeutic or "problem" literature for young people. Literature featuring illness, anorexia, bereavement, transgender issues or characters with dyslexia or autism, for example, attract both positive and negative comment from reviewers with either first-hand or indirect experience. These reviewers can effectively co-create insightful and informed discussions of a particular text, pointing out perceived biases, distortions or inaccuracies, praising content that recognisably reflects an individual's experience, or recounting how a text has been used in a personal or educational context. There is considerable scope for research to explore the extent to which themes of authenticity and inclusive values, as applied to the tacitly or explicitly approved purposes of children's literature, underpin such reviews.

\section{Drawing on Dissenting Outsider Voices to Broaden the Critical Debate}

The examples presented in this final section illustrate what academic studies could gain by drawing on voices from outside the academy. Here the first challenge is not to locate views that are in any sense representative, but to recognise that academic scholarship can at times omit certain perspectives, or miss critical points, while outside voices can be capable of providing what was missing. With such a vast amount of potential resource there needs to be a rationale for selecting any reviews to be discussed, with attention both to context and to methods of analysis. Putting the focus on dissent immediately points to one aspect of context, in that there may be an existing professional or academic consensus in the secondary texts surrounding a particular work of children's literature which is exclusively or mainly positive. That may not present any problem when the aim is to introduce trainee teachers to potentially useful texts, but when students are expected to engage with critical literature it is problematic if there is an absence of critical debate. In that case, a significant challenge to the academic consensus might only come from a different quarter. An outsider voice may raise not only a dissenting point, but one that has not yet been considered in published academic criticism. Dissenting outsider opinion can serve to test or even refute claims made in academic criticism about a text's general reception or reader response. No claims should or could be made about the representative nature of isolated, quoted comments from reviews without further and sufficient evidence. On the other hand, drawing on reviews as qualitative data can be enough to query broad general claims or reveal where there 
has perhaps been an unfounded consensus about a book's imagined reception, as in the following examples.

Wolf Erlbruch's Duck, Death and the Tulip (2007, translation 2008) is a widely celebrated picture book that has been recommended for its educational and therapeutic value in treating the subject of death. Angela Wiseman (2013) notes an increase in the number of children's books related to death and grief published in the last 20 years, along with studies suggesting that 'bibliotherapy' can help children deal with difficult emotions. Janet Evans' discussion of the book is entirely positive to the extent of stating that "everything about it is beautiful" (2014, p. 188). Lesley Clement's analysis (2013) considers the personification of death in the context of a 'warming' relationship between the characters Duck and Death, and refers to the "tenderness of Death" in her analysis of Erlbruch's text and images. Meg Rosoff's review (2009) in a mainstream newspaper also describes the depiction of Death's actions as 'infinitely tender'. Many of the online reviews for Duck, Death and the Tulip refer to its adaptations as an animated film or play, rather than the original book, and tend to reproduce similar or identical descriptions and recommendations, with recurring phrases such as 'heart-warming' (also found in the publisher's promotional material). In contrast, a greater range of comment is to be found on Amazon's UK and US sites, in sets of reviews that can be analysed in various ways. The specific format is shown for verified purchases, so on the UK site it can be seen that $20 \%$ of verified purchasers writing reviews bought the 'School \& Library binding' version rather than the paperback. A number of reviewers also identified themselves as purchasing for school or class use. Turning to the topics covered, the most frequent was suitability for particular age groups, with opinion varying as to whether the book was ideal or too frightening for young children, or might even as the publisher suggests be recommended for teenagers and adults. Comments that death featuring in a picturebook for children is surprising or unusual also appear frequently. Several reviewers name possible contexts of use, for instance as a sensitive introduction to a conversation about death with a young child. On both the UK and US sites reviews are mainly positive, contributing to the overall impression of a strongly favourable consensus.

On the other hand Amazon reviews are also where critiques can be found that explicitly refer to and break with this consensus. One reviewer commented that the book "was supposed to be trendy" but that they would not recommend it; another referred to buying a copy after reading Rosoff's (2009) review from which they now dissented, and returning the book. Among dissenting voices, some challenge the text's apparent philosophical approach, along with its representation and implicit "explanation" of death and dying. One such review received two responses, creating a debate in miniature about what adults might tell children about death, and whether explaining it is even appropriate or necessary. Another more extensive critique (Hill, 2014) raises new points.

The story it tells about death and dying could not be more trite... Duck has no family and exists in an endless, "Zen", off-white background - so her life and death are pretty meaningless. Her death doesn't have a cause, it just occurs and it's the only discernible event in her life. 
Moral judgements and arguments about suitability for specific age ranges inevitably surface most obviously in online reviews of the most controversial YA novels. Kevin Brooks' The Bunker Diary (2013) attracted several mainstream press articles about its philosophical message, moral values and status as appropriate reading for the young, especially after it was awarded the prestigious Carnegie Medal in 2014. Amanda Craig (2014) noted that she had refused to review the book on publication, because of its lack of humanism or redemption. Lorna Bradbury (2014) criticised the publisher's failure to provide warnings of the content, described the reading experience as akin to the characters' experience of "being manipulated by a psychopath and pervert", and argued that "[the] question we should be asking ourselves, given the success of The Bunker Diary, as well as other similar fictions, is whether this nihilistic diet is good for our teenagers." In response, the award judges publicly defended their selection in terms of finding hope and humanity in the book and having no regard to its alleged shock value in making the award.

These are authoritative voices, and turning to the democracy of online critics, the absence of such status lends a freer air to the debate. There is less sense of a heavy responsibility towards the young, and much more direct criticism aimed at the author personally, and his work, for artistic rather than moral failings, as reviewers do not feel obliged to use polite, impersonal academic language. One of the clearest examples is Andrew Wright's lengthy review (2014) which also addresses, but then sets aside, the mainstream press criticism and moral outrage.

Brilliant stuff so far. Superb writing. Great set-up. Could even win the Carnegie! Now; finish it. No, I don't want happy or hopeful necessary [sic] but the reader must have a resolution for this to be a story. How, you ask? You're the writer, use your imagination.

In other reviews, younger readers who stated their ages also criticised plot flaws rather than any implied message. With The Bunker Diary as with other reviews of YA fiction, comments on age-appropriacy are met with objections from young readers writing their own positive accounts of a reading experience.

An alternative quantitative approach could be adopted to analyse a large number of reviews in order to research embedded constructions of childhood or moral attitudes towards children's literature, among other possible goals. That alternative approach to working with online data is not discussed here, but there is certainly a case for encouraging students to learn and understand appropriate methods and acquire skills for working with big data. Especially with young adult fiction, there is a more substantial amount of direct reader response amongst online reviews, so quantitative analyses become a distinct possibility. A possible analytic aim for students might be to compare the main topics covered in reviewers' comments with hypotheses about reader response, returning us to the debate about actual versus notionally positioned readers. Suzanne Collins' best-selling series The Hunger Games (2009) features in many thousands of easily searchable online reviews, offering critiques that might accord with, or differ substantially from, critiques in the already fairly substantial academic literature. Katherine Broad (2013) for example considers the overlap between traditional romance literature and dystopian YA fiction, a topic that also intensely engages many young online reviewers, but 
who are often highly critical of the romance elements. The range of opinion expressed makes it impossible to generalise about the trilogy's gendered effects on young readers, but analysis could identify the most common themes.

\section{Conclusion}

Online reviews written by people who are neither academics nor professionals do more than show how some readers think and talk about children's literature. They can call an apparent critical consensus or the influence of more prestigious commentaries into question, introduce new perspectives into debates around a text, contribute grounded accounts of texts in use and the responses of diverse readers, and challenge the authenticity of depictions of events, settings and experiences from positions of personal knowledge.

Researching these outsider perspectives, given their open accessibility, is feasible for undergraduate students with limited time as well as for scholars able to conduct in-depth and extensive analyses. Both at introductory levels and for longer term studies, attending to the wider democracy of children's literature critics can open up and transform criticism and debate. Simple search and filtering tools already exist but researchers in addition need to be able to define and refine a methodological approach, and pay careful attention to the influence of the online platforms themselves. A selective use of individual reader responses cannot substitute for paying the democracy of children's literature critics fuller and more serious attention. Above all, the diversity of the authors of online reviews and of their opinions should alert students and researchers to the importance of avoiding generalisations about the influence of texts on young readers, without robust evidence. Paradoxically, too, attending to personal responses can develop criticality, remind students why and how academic scholarship and expertise differ from reviews, and help them value those differences.

Open Access This article is distributed under the terms of the Creative Commons Attribution 4.0 International License (http://creativecommons.org/licenses/by/4.0/), which permits unrestricted use, distribution, and reproduction in any medium, provided you give appropriate credit to the original author(s) and the source, provide a link to the Creative Commons license, and indicate if changes were made.

\section{References}

Amazon Customer. (2012). Better than I Expected Really. Amazon Customer Reviews. Accessed October 24, 2016, from https://www.amazon.com/gp/customer-reviews/R3TSXLCHTPZD1I/ref=cm_cr_ getr_d_rvw_ttl?ie=UTF8\&ASIN=0439023521.

Amazon Customer Review Creation Guidelines. (2016). Accessed October 24, 2016, from https://www. amazon.co.uk/gp/help/customer/display.html/?\&nodeId=201723570.

Arizpe, Evelyn, and Styles, Morag. (2015). Children Reading Picturebooks: Interpreting Visual Texts. Oxford: Routledge.

Attar, Dena, and Maybin, Janet. (2016). The Contribution of Children's Literature Studies. In Ann Hewings, Lynda Prescott, and Philip Seargeant (Eds.), Futures for English Studies (pp. 179-196). Basingstoke: Palgrave Macmillan. 
Barton, David, Hamilton, Mary, and Ivaniç, Roz (Eds.). (2000). Situated Literacies: Reading and Writing in Context. London: Routledge.

Baym, Nancy K. (2015). Social Media and the Struggle for Society. Social Media + Society, 1(1), 1-2. Bradbury, Lorna. (2014, June 24). The Bunker Diary: Why Wish This Book on A Child? The Telegraph. http://www.telegraph.co.uk/culture/books/10920101/The-Bunker-Diary-why-wish-this-book-on-achild.html.

Broad, Katherine R. (2013). The Dandelion in the Spring: Utopia as Romance in Suzanne Collins's The Hunger Games Trilogy. In Carrie Hintz, Balaka Basu, and Katherine R. Broad (Eds.), Contemporary Dystopian Fiction for Young Adults: Brave New Teenagers (pp. 117-130). New York: Routledge.

Brooks, Kevin. (2013). The Bunker Diary. London: Puffin Books.

Chen, Hua-Ning, and Huang, Chun-Yao. (2013). An Investigation into Online Reviewers' Behaviour. European Journal of Marketing, 47(10), 1758-1773.

Clement, Lesley. (2013). Death and the Empathic Embrace in Four Contemporary Picture Books. Bookbird: A Journal of International Children's Literature, 51(4), 1-10.

Collins, S. (2008). The Hunger Games. New York: Scholastic.

Collins, S. (2009). Catching Fire. New York: Scholastic.

Collins, S. (2010). Mockingjay. New York: Scholastic.

Couldry, N., and van Dijck, J. (2015). Researching Social Media as if the Social Mattered. Social Media + Society, 1(2), 1-7.

Craig, Amanda. (2014, June 24). The Bunker Diary: Should Books have Happy Endings? The Independent. http://www.independent.co.uk/arts-entertainment/books/features/the-bunker-diaryshould-books-have-happy-endings-9560752.html.

Donaldson, Julia and Scheffler, Axel. (2014). The Scarecrows' Wedding. Alison Green Books.

Downey, Gregory J. (2014). Making Media Work: Time, Space, Identity and Labor in the Analysis of Information and Communication Infrastructures. In Tarleton Gillespie, et al. (Eds.), Media Technologies: Essays on Communication, Materiality, and Society (pp. 141-165). Cambridge, MA: MIT.

Eccleshare, Julia. (2015). From Writer to Reader-What Role Do Reviews Play in the Children's Book Market? In 22nd Annual NCRCL/IBBY UK Conference, 14 November 2015.

Erlbruch, Wolf. (2008). Duck, Death and the Tulip. Auckland: Gecko.

Evans, Janet. (2014). Audience, Theme and Symbolism in Wolf Erlbruch's Duck, Death and the Tulip. In Bettina Kümmerling-Meibauer (Ed.), Picturebooks: Representation and Narration (pp. 185-200). New York: Routledge.

Gubar, Marah. (2013). Risky Business: Talking about Children in Children's Literature Criticism. Children's Literature Association Quarterly, 38(4), 450-457.

Hill, D.A. (2014). Disappointed. Amazon Product Reviews. Accessed February 11, 2016, from https:// www.amazon.co.uk/product-reviews/1877467170/ref=cm_cr_arp_d_viewopt_sr?ie=UTF8\&reviewer Type=all_reviews\&showViewpoints=1\&sortBy=helpful\&filterByStar=one_star\&pageNumber $=1$.

Hoffert, Barbara. (2010). Every Reader a Reviewer. Library Journal, 135, 22-25.

Johnston, Rosemary Ross. (2011). Reader Response. In M.O. Grenby and K. Reynolds (Eds.), Children's Literature Studies: A Research Handbook (pp. 133-141). Basingstoke: Palgrave MacMillan.

Kennedy, Amy. (2012). Author Studies: An Effective Strategy for Engaging Pre-Service Teachers in the Study of Children's Literature. Children's Literature in Education, 43(1), 107-111.

Kindle Customer. (2013). Great Dis-topia Future Story. Amazon Customer Reviews. Accessed October 24, 2016, from https://www.amazon.com/gp/customer-reviews/R2UUMVW0ZYWZSH/ref=cm_cr_ getr_d_rvw_ttl?ie=UTF8\&ASIN=0439023521.

Kokkodis, Marios, and Lappas, Theodoros. (2015). The Effect of Disclosing Purchase Information on Review Helpfulness: Evidence from Amazon.com. In Thirty Sixth International Conference on Information Systems, Fort Worth 2015.

Mills, Kathy Ann. (2014). A Review of the "Digital Turn" in the New Literacy Studies. Review of Educational Research, 80(2), 246-271.

Nikolajeva, Maria. (2014). Reading for Learning. Cognitive Approaches to Children's Literature. Amsterdam: John Benjamins.

Nodelman, Perry. (2016). The Hidden Child in The Hidden Adult. Jeunesse: Young People, Texts, Cultures, 8(1), 266-277.

Rosoff, Meg. (2009, December 19). Duck, Death and the Tulip by Wolf Erlbruch. The Guardian. Accessed February 11, 2016, from https://www.theguardian.com/books/2009/dec/19/wolf-erlbruchchildren-picturebook-review. 
Rudd, David. (2013). Reading the Child in Children's Literature: An Heretical Approach. New York: Palgrave Macmillan.

Seargeant, Philip, and Tagg, Caroline (Eds.). (2014). The Language of Social Media: Identity and Community on the Internet. Basingstoke: Palgrave Macmillan.

Shen, Wenqi, Hu, Yu Jeffrey, and Rees, Jackie. (2015). Competing for Attention: An Empirical Study of Online Reviewers' Strategic Behaviour. MIS Quarterly, 39(3), 683-696.

Shirky, Clay. (2008). Here Comes Everybody: The Power of Organizing Without Organizations. New York: Allen Lane.

Snyder, Ilana (Ed.). (2002). Silicon Literacies: Communication, Innovation and Education in the Electronic Age. London: Routledge.

Street, Brian V. (1995). Social Literacies: Critical Approaches to Literacy in Development, Ethnography and Education. London: Longman.

Tapscott, Donald, and Williams, Anthony. (2007). Wikinomics: How Mass Collaboration Changes Everything. London: Atlantic Books.

The Economist. (1999, August 28). Amateurs on Amazon. The Economist.

The Economist. (2015, October 24). Five Star Fakes; Reviews on Amazon. The Economist.

Vásquez, Camilla. (2013). Narrativity and Involvement in Online Consumer Reviews: The Case of TripAdvisor. Narrative Inquiry, 22(1), 105-121.

Vásquez, Camilla. (2014). The Discourse of Online Consumer Reviews. London:Bloomsbury Publishing. Wiseman, Angela M. (2013). Summer's End and Sad Goodbyes: Children's Picturebooks About Death and Dying. Children's Literature in Education, 44, 1-14.

Wright, Andrew. (2014). A Challenging Piece of Art Work, But not a Story. Stopping Isn't an Ending. Amazon Product Reviews. https://www.amazon.co.uk/gp/customer-reviews/R24TG8AS2P26ST/ ref=cm_cr_pr_rvw_ttl?ie=UTF8\&ASIN=B00ADNP5VS. 